\title{
Revisions to the Canadian Emergency Department Triage and Acuity Scale (CTAS) Guidelines 2016
}

\author{
Michael J. Bullard, MD*; Erin Musgrave, $\mathrm{MN}, \mathrm{RN}^{\dagger}$; David Warren, $\mathrm{MD}^{\ddagger}$; Bernard Unger, $\mathrm{MD}^{\S}$; \\ Thora Skeldon, RN, BSN"; Rob Grierson, MD"; Etienne van der Linde, $\mathrm{MD}^{*{ }^{* \dagger} \text {; }}$ \\ Janel Swain, ACP, BSc, BEd ${ }^{\ddagger \neq}$; on behalf of the CTAS National Working Group
}

\section{INTRODUCTION}

The Canadian Triage and Acuity Scale (CTAS) was introduced in $1999^{1}$ after studying the successful National Triage Scale (NTS) from Australia. ${ }^{2}$ The Canadian Association of Emergency Physicians (CAEP), National Emergency Nurses Association (NENA), l'Association des médecins d'urgence du Québec (AMUQ), and the Society of Rural Physicians of Canada (SRPC) formed the CTAS National Working Group to promote its use in Canada. Recognizing that children from neonate to adolescent were not adequately differentiated based on an adult centric triage tool the Canadian Paediatric Society (CPS) approached the CTAS NWG and in collaboration published the Canadian Paediatric Triage and Acuity Scale in 2001. ${ }^{3}$ In 2003 the Canadian Emergency Department Information System (CEDIS) National Working Group published a standardized national ED presenting complaint list which offered an inviting framework for CTAS to build on. ${ }^{4}$ In 2004 adult CTAS was reformulated, using the 17 CEDIS complaint groups and the 165 complaints, primary or $1^{\text {st }}$ order modifiers were defined based on vital signs, pain, and mechanism of injury, to help nurses assign an appropriate triage score. ${ }^{5}$ To further refine the appropriate prioritization, special or $2^{\text {nd }}$ order modifiers were identified for certain complaints or groups of complaints where the $1^{\text {st }}$ order modifiers were inadequate. Mental health complaints have primarily $2^{\text {nd }}$ order modifiers as acuity and risk for these patients are rarely adequately defined by vital signs or pain. For patients with "chest pain, non cardiac features", 'ripping, tearing' pain is a CTAS level 2 modifier to try to avoid missing an aortic dissection.

In 2008 there was a collective review of and update of the CEDIS complaint list, Adult CTAS and Paediatric CTAS to align them in terms of timing and of structural congruence by adding paediatric definitions and $2^{\text {nd }}$ order modifiers, and a few paediatric specific CEDIS complaints. $^{6-8}$ As noted previously the structure for CTAS based on a standardized presenting complaint list and defined modifiers to assign triage acuity began in 2004, and all subsequent publications build on this document. It was also decided that updates would be undertaken every 4 years. The 2012 update was relatively minor and was e-published in 2013. ${ }^{9}$ The 2016 review and revisions has been extensive and while it will not lead to major changes in CTAS itself, a great deal of energy has gone into improving the educational materials and processes which will be outlined within the document.

\section{RATIONALE FOR CHANGE}

The CTAS NWG receives and responds to questions and suggestions from CTAS instructors, emergency nurses, administrators, our international partners, and patients on a regular basis. We respond to requests received through the CTAS NWG members on behalf of their organizations: CAEP, NENA, AMUQ, SRPC, CPS, and most recently the Paramedic Chiefs of

From the *University of Alberta Hospital, University of Alberta, Edmonton, AB; †Horizon Health Network, Miramichi, NB; $¥$ Children’s Hospital, London Health Sciences Centre, University of Western Ontario, London, ON; §Jewish General Hospital, McGill University, Montreal, QB; ๆAlberta Health Services, Rimbey, AB; \|Health Sciences Winnipeg, University of Manitoba, Winnipeg, MB; **G.B. Cross Memorial Hospital, Clarenville, NL; ††Memorial University, St. John's, NL; and the ¥¥Emergency Health Services Nova Scotia, Dartmouth, NS.

Corresponding to: Dr. Michael J. Bullard, University of Alberta Hospital, University of Alberta, Edmonton, AB T6G 2T4; Email: mbullard@ ualberta.ca 
Canada (PCC). Requests are also received through the Canadian Institute for Health Information (CIHI) who co-manages the CEDIS Complaint list with the CTAS NWG. More recently the Society of Obstetricians and Gynaecologists of Canada have collaborated on the development of the Obstetrical Triage Acuity Scale (OTAS) that has provided another opportunity for CTAS advancement and alignment. ${ }^{10}$ To prepare for this update CTAS NWG Instructors, nationally, were surveyed for their suggestions which were then organized and brought back to the committee for review and consideration.

This update focuses on the following key areas:

1. Review and clarity regarding triage acuity time targets

2. Addressing the practice of using CTAS as a tool to divert patients away from the ED

3. Presenting CEDIS complaint additions and modifications

4. Introduction of 'heat related issue' along with special modifiers

5. Revised pregnancy modifiers accompanied by the introduction 'post-partum issues' and special modifiers

6. Introduction of a new frailty modifier

7. Development and presentation of a new geriatric educational component recognizing the challenges associated with our fastest growing demographic

8. Paediatric updates focusing on fever standards and recognizing hypertension in children

9. Welcoming the Paramedic Chiefs of Canada as the newest member organization of the CTAS NWG and updating the plans for Prehospital CTAS (PreCTAS)

10. Introducing planned changes in the education process, teaching materials and CTAS certification

\section{$\underline{\text { METHODS }}$}

The revisions have been at iterative process based on feedback from our key stakeholders, the CTAS Instructors and Providers, the general public, the CTAS NWG member organizations, the Canadian Institute of Health Information through their National Ambulatory Care Reporting System (NACRS) representatives and health administrators. Increasing demand for health care services within a constrained economy has led to requests from administrators and providers to alter the recommended CTAS time targets based on acuity, pointing out that very few hospitals are able to meet them. Some jurisdictions are even declaring that CTAS level 4 and 5 patients should be treated in the community and in some cases mandating deferral from the ED to primary or urgent care centres. The CTAS NWG and NACRS receive a number of requests each year, for additions or changes to the CEDIS complaint list. In many cases articulating which current complaint is applicable is sufficient to satisfy these requests. For the remaining requests a group of Computer Emergency Department Information System (CEDIS) NWG and CTAS NWG members adjudicated them to reach a consensus.

Heat related issue was an addition previously made by 2 of our international partners, Japan and Saudi Arabia, and with global temperatures continuing to rise it was deemed important to add this to our Environmental complaints group. The OTAS working group engaged the CTAS NWG during their development recognizing the value of adopting our first order modifiers and definitions wherever our tools matched. This allowed us to review our pregnancy modifiers and educational components and determine the value of updating and aligning with OTAS in key common areas.

The CTAS NWG has long recognized the challenge that the elderly pose at triage based on a number of factors including knowledge of their premorbid condition, communication difficulties, factors influencing physiologic parameters and variable presentations of common conditions. As our aging population continues to grow and the medical system struggles to meet the demands, the emergency department often becomes the destination of choice to sort out a myriad of medical and non medical problems. To address concerns that certain groups of the patient population are more prone to deterioration with long waits to be seen, a frailty modifier has been developed to help identify these patients and to up-triage them to a CTAS level 3 to ensure they don't get missed. The frailty modifier and the new geriatric educational components have been developed in collaboration with the CAEP Geriatric Emergency Medicine Practice Committee. Paediatric updates are developed in collaboration with the Canadian Paediatric Society.

Several jurisdictions have been using CTAS in prehospital practice to support communication with their emergency department colleagues, with the province of 
Ontario legislating its use in 2009. The recent addition of the Paramedic Chiefs of Canada in 2016 now allows for a 2-way dialogue with the CTAS NWG and the opportunity to ensure Prehospital CTAS has improved sensibility. With more and more educational initiatives developing online educational opportunities, it was recognized that for our CTAS Providers, especially in rural and remote locations, this is required. This manuscript will highlight all of the updates for CTAS 2016 and be accompanied by a second publication expanding on the Geriatric triage teachings, as well as another publication focusing on the present and future role of Pre-CTAS.

\section{REVISIONS}

\section{CTAS time targets}

While it has been suggested that the recommended triage response times be lengthened because few emergency departments will ever be able to meet them, the CTAS levels 1-5 acuity time targets will remain unchanged.

\section{Rationale}

While the $80-95 \%$ 'fractile response time' targets proposed in the 1999 CTAS Implementation Guidelines ${ }^{1}$ are not achievable by busy EDs, the CTAS acuity time targets were developed to ensure appropriate patient prioritization. We would propose replacing fractile response rates with 'benchmarking' ED performance metrics in line with the CAEP position paper published in 2013. ${ }^{11}$ The overall goal for triage to physician initial assessment is a median of 1 hours and $90^{\text {th }}$ percentile of 3 hours. Within this framework access and throughput needs to be optimized to ensure CTAS level 1 patients are seen immediately and sick CTAS level 2 and 3 patients within as timely a manner as possible. This allows individual sites to compare year on year time targets and also the opportunity to contrast performance metrics with provincial and national EDs with similar resources and serving similar patient populations and learn from high performing institutions. What is important to understand is that the 5 CTAS acuity/ risk levels and their respective modifiers have been developed to be highly sensitive but not specific.

An 'immediate' response to life or limb threatening presentations doesn't need clarification, however, many CTAS level 2 or CTAS level 3 patients will not suffer from delays in care beyond the 15 and 30 minute targets. The key is that within their respective cohorts selected patients do need timely care and the clinical experience of the triage nurse, and safe ED processes, will support those goals. Examples include performing an ECG on all "chest pain, cardiac features" and having a physician review within 15 minutes to avoid missing an ST elevation infarct and to also expedite those patients with ongoing pain. For stable patients with "extremity weakness / symptoms of CVA" within the therapeutic window, CTAS level 2, activating the stroke team or having a direct to CT scan protocol may shorten the door to needle time for eligible patients. High risk mechanism of injury patients may be stable on arrival but still triaged as CTAS level 2. They should not displace lower acuity patients in more distress but be placed in an internal waiting room or close line of site to be carefully observed for signs of deterioration while waiting for physician assessment (this is a high risk rather than high acuity patient). Many CTAS level 2 and CTAS level 3 patients present with moderate to severe pain conditions. In some cases these are signals of a life threatening condition but in all cases they should be afforded timely analgesia. With a heightened awareness of the dangers of delayed recognition and management of sepsis (3 SIRS criteria), CTAS level 2 and (2 SIRS criteria looks unwell) level 3, processes need to be in place to assess and prioritize post triage. Dislocations and displaced fractures are CTAS level 3. While delays may not lead to bad outcomes, reducing these injuries significantly improve comfort and satisfaction. CTAS level 4 and 5 patients are by definition stable, yet admission rates can be as high as $10 \%$ and $4 \%$ respectively, indicating many of them require careful workups.

\section{CTAS as a diversion tool}

As our population continues to grow and to age Emergency Department visits remain high and wait times continue to be an issue largely as a result of system overcrowding. All efforts to resolve this problem through improved ED efficiencies have failed because they cannot address the issues of timely access to care in the community and lack of inpatient and long-termcare spaces to support rapid outflow of patients from the ED. ${ }^{11}$ Recently a number of administrators have sought to co-opt CTAS as a tool to identify 'inappropriate ED visits', with plans to divert them away 
from the emergency department. In addition, retrospective reviews of discharged ED patients have attempted to define 'primary care appropriate' ED diagnoses and calculate the per cent of patients who are "misusing" the emergency departments.

Without a presentation specific deferral algorithm and methodologically sound research to support safety, efficacy, and patient satisfaction deferral policies away from the ED should be tempered, and CTAS should not be applied to make these decisions.

\section{Rationale}

i) CTAS was developed to prioritize ED patients based on acuity and risk and was never designed to identify patients who were inappropriate.

ii) The US Emergency Medical Treatment and Labor Act (EMTALA) in 1994 defined an emergency medical condition as "any medical or behavioural condition of recent onset and severity, including but not limited to severe pain, that would lead a prudent layperson, possessing an average knowledge of medicine and health, to believe that his or her condition, sickness or injury is of such a nature that failure to obtain immediate medical care could result in placing the patient's health in serious jeopardy, cause serious impairment to bodily functions, serious dysfunction of any bodily organ or part, or in the case of a behavioral condition placing the health of such person or others in serious jeopardy".

iii) A number of studies have shown that non EMS patients have already tried different options to access care or have decided the ED is the best option for their problem. ${ }^{12,13}$

iv) Those studies looking at deferral or refusal of care for patients triaged as low acuity have noted this practice to be "measurably unsafe and will lead to inappropriate refusal of care for patients requiring hospital treatment". ${ }^{14-16}$ Admission rates for CTAS level 4 s vary from $3-10 \%$ and for CTAS level 5 from $1-4 \%$ both nationally and internationally. ${ }^{17}$

v) A study looking at presenting complaint and discharge diagnosis to see if discharge diagnosis could be used to identify nonemergency visits found that while $6.3 \%$ of patients at discharge could have been treated in a primary care setting, the same presenting complaints were reported for $88 \%$ of all ED visits, indicating the need for a careful medical assessment prior to consideration to defer. $^{18}$

\section{CEDIS Complaint updates}

While the CTAS NWG and NACRS receive numerous requests for new CEDIS complaints or name changes, the goal is to limit these as much as possible to support the education and adoption of CTAS revisions.

\section{Rationale}

In many instances, understanding the reason for a CEDIS complaint change or addition, allows for a clear explanation as to which existing complaint should be selected and applied. There were, however, a few wording changes that made sense and 3 new complaints added based on work with the Obstetrical Triage Acuity Scale group, climate change, and the number of emergency departments who provide scheduled revisits for treatment (Table 1).

Two complaints changed category with Cast check moving from General and minor to Orthopedic and Removal of staples/sutures from General and minor to Skin. The NACRS CEDIS Presenting Complaint List (V5.0) contains these changes and can be accessed at http://caep.ca/resources/ctas/cedis.

\section{Heat related issue}

\section{Rationale}

As climate change continues to warm the atmosphere, with 2016 being the hottest year on record, heat related presentations to the emergency department will become more common. Both our Japanese and Saudi Arabian CTAS adopters had already identified this as a deficiency. Heat stroke is a life-threatening emergency and requires immediate cooling and resuscitation while patients with heat exhaustion can deteriorate if not appropriately evaluated and managed. ${ }^{19,20}$ See Table 2 for the relevant modifiers.

\section{Obstetrical/Gynaecological revisions}

\section{Rationale}

Over the last two years the National Obstetrical Triage Working Group built on the work of the London Health Sciences Centre group who developed the Obstetrical Triage Acuity Scale (OTAS). They 


\begin{tabular}{|lll|}
\hline Table 1. New or Revised Adult Presenting Complaint & \\
\hline CEDIS Complaint Category & Previous Complaint & New or Revised Complaint \\
\hline Cardiovascular & Bilateral leg swelling/edema & Leg swelling/edema \\
Environmental & No previous & Heat related issue \\
Obstetrical-Gynaecological & No previous & Post partum issue \\
Trauma & Major trauma - blunt & Multisystem trauma - blunt \\
& Major trauma - penetrating & Multisystem trauma - penetrating \\
General and Minor & No previous & Return visit for therapy \\
& Imaging test & Imaging test/blood test \\
& Abnormal lab values & Abnormal lab/imaging results \\
\hline CEDIS = Canadian Emergency Department Information System. & \\
\hline
\end{tabular}

\begin{tabular}{|c|c|c|}
\hline Presenting & & CTAS \\
\hline Complaint & Modifiers & Level(s) \\
\hline \multirow[t]{13}{*}{ Heat related issue } & & $1-4$ \\
\hline & Respiratory distress & $1-3$ \\
\hline & Hemodynamic status & $1-3$ \\
\hline & Level of consciousness & $1-2$ \\
\hline & Pain score (peripheral) & $3-4$ \\
\hline & Frailty & 3 \\
\hline & Core temperature greater than $41^{\circ} \mathrm{C}$ & 1 \\
\hline & Severe dehydration & 1 \\
\hline & Core temperature $39^{\circ}-41^{\circ} \mathrm{C}$ & 2 \\
\hline & Moderate dehydration & 2 \\
\hline & Ongoing heat cramps & 3 \\
\hline & Mild dehydration & 3 \\
\hline & $\begin{array}{l}\text { Heat cramps resolving, well } \\
\text { hydrated }\end{array}$ & 4 \\
\hline
\end{tabular}

recognized that CTAS did include pregnancy issues, but felt this was inadequate for the needs of the delivery room. When contacting the CTAS NWG for advice, the former Co-Chair, joined their working group, which allowed for sharing and borrowing of knowledge. They adopted the CTAS vital sign modifiers while CTAS adopted and revised a number of the special modifiers. ${ }^{21}$ It was also realized that CTAS did not currently address post pregnancy presentations so Post partum issues was added (Table 3 ).

\section{New Frailty modifier}

\section{Rationale}

As volume and capacity pressures on emergency departments continue, certain groups are at risk for prolonged wait times who run a greater risk of deteriorating or suffering unduly. These include: the frail elderly, those who are physically disabled, cognitively challenged, with debilitating diseases, or homeless, especially if unaccompanied.

Studies show increased ED wait times lead to delayed analgesia, delayed antibiotics, higher ICU admissions and increasing mortality rates for all patients with the elderly even more susceptible. ${ }^{22-26}$ Holding vulnerable patients, with dementia and/or multiple comorbidities in a waiting room, with the potential for dehydration, untreated pain, increasing fatigue and immobility, can lead to the precipitation of delirium. ${ }^{27,28}$

The introduction of a CTAS level 3 'frailty modifier' will allow triage nurses to up-triage such patients normally rated as a CTAS level 4 or 5 .

\section{Frailty modifier definition}

Any patient completely dependent for personal care; who is wheelchair-bound; suffers from cognitive impairment that limits their awareness of their surroundings or ability to appreciate time; is in the late course of a terminal illness; is showing signs of cachexia and general weakness; or is over 80 years of age unless obviously physically and mentally robust. ${ }^{29,30}$

\section{Geriatric triage considerations}

\section{Rationale}

The over 65 year old age group is our fastest growing population demographic as baby boomers reach retirement age and are expected to represent $20 \%$ of the population by 2030. There has been a parallel rise in ED visits by this group and they tend to be more complex, require more resource utilization and have higher admission rates. ${ }^{31,32}$ 


\section{Table 3. New Obs/Gyn Complaint and Revised Special Modifiers}

\begin{tabular}{|c|c|c|c|}
\hline Presenting Complaint & Previous Special Modifiers & Revised Special Modifiers & CTAS Level \\
\hline \multirow[t]{17}{*}{ Pregnancy issues $>20$ weeks } & presenting fetal parts, prolapsed cord & presenting fetal parts or prolapsed cord & 1 \\
\hline & \multirow[t]{4}{*}{ vaginal bleeding 3rd trimester } & active vaginal bleeding & 1 \\
\hline & & actively seizing or postictal & 1 \\
\hline & & penetrating abdominal trauma in pregnancy $>20$ weeks & 1 \\
\hline & & no fetal movement & 1 \\
\hline & \multirow[t]{2}{*}{ active labour (contractions less than or equal to $2 \mathrm{~min}$ ) } & active labour (contractions less than or equal to $5 \mathrm{~min}$ ) & 2 \\
\hline & & unplanned / unattended birth & 2 \\
\hline & no fetal movement / no fetal heart tones & decreased fetal movement & 2 \\
\hline & \multirow[t]{3}{*}{ headache $+/$ - edema $+/$ - abdo pain $+/$-hypertension } & headache + /- edema + /- epigastric pain + /-visual disturbance + /- CVA symptoms & 2 \\
\hline & & hypertension SBP greater than 160 and DBP greater then 100 & 2 \\
\hline & & major blunt trauma in pregnancy $>20$ weeks & 2 \\
\hline & post delivery & high risk substance abuse & 2 \\
\hline & \multirow[t]{4}{*}{ active labour (contractions greater than $2 \mathrm{~min}$ ) } & active labour (contractions greater than $5 \mathrm{~min}$ ) & 3 \\
\hline & & history of bleeding prior to presentation & 3 \\
\hline & & hypertension SBP greater than 140 and DBP greater than 90 & 3 \\
\hline & & minor trauma - no direct abdominal trauma & 3 \\
\hline & \multirow[t]{2}{*}{ possible leaking amniotic fluid } & Vaginal fluid loss & 3 \\
\hline \multirow[t]{8}{*}{ Pregnancy issues $<20$ weeks } & & pelvic pressure with abdominal cramping, back pain & 2 \\
\hline & \multirow[t]{3}{*}{ heavy vaginal bleeding $+/$ - pregnancy } & heavy vaginal bleeding & 2 \\
\hline & & cramping & 3 \\
\hline & & possible vaginal fluid leak & 3 \\
\hline & vaginal bleeding - normal VS & mild to moderate vaginal bleeding & 3 \\
\hline & \multirow[t]{3}{*}{ vaginal bleeding - minor / spotting } & spotting & 4 \\
\hline & & pink, mucous discharge & 5 \\
\hline & & vaginal discharge & 5 \\
\hline \multirow[t]{14}{*}{ Postpartum issues* } & & actively seizing or postictal & 1 \\
\hline & & active vaginal bleeding with clots & 2 \\
\hline & & headache + /- edema + /- epigastric pain + /-visual disturbance + /- CVA symptoms & 2 \\
\hline & & hypertension SBP greater than 160 and DBP greater than 100 & 2 \\
\hline & & chills, wound redness or purulent drainage & 2 \\
\hline & & pelvic pain with abnormal vaginal discharge & 2 \\
\hline & & unable to empty bladder/dysuria less than $72 \mathrm{hrs}$ postpartum & 2 \\
\hline & & high risk substance abuse & 2 \\
\hline & & bright red bleeding/spotting less than 5 days postpartum & 3 \\
\hline & & persistent headache post epidural anesthesia with delivery & 3 \\
\hline & & mild/moderate headache $+/$ - non dependant edema & 3 \\
\hline & & hypertension SBP greater than 140 and DBP greater than 90 & 3 \\
\hline & & wound redness/swelling $+/$ - serosanguinous drainage & 3 \\
\hline & & bleeding/spotting + cramping greater than 10 days postpartum & 4 \\
\hline
\end{tabular}


A number of factors lead to triage challenges among this population and may lead to under-triage placing some patients at increased risk. While there are many changes associated with aging and chronic disease, we have focused on 3 key areas:

i) Homeostatic mechanism changes make vital sign interpretation more challenging.

a. Respiratory: Aging lungs have less elastic recoil, more dead space and decreased physiologic reserve. ${ }^{33}$ A respiratory rate of greater than 27 breaths / minute is a sensitive predictor of adverse events and identifying critically ill patients. ${ }^{34}$

b. Hemodynamic: Myocardial thickening, arterial wall stiffness, and hypertension lead to increased workload on the heart. Wider pulse pressures and a decreased response to circulating catecholamines can lead to orthostatic hypotension even without the influence of medications. ${ }^{35}$ A systolic blood pressure of less than $110 \mathrm{mmHg}$ often represents hypotension in the older population especially among trauma victims. ${ }^{36}$ The resting heart rate also increases with age. ${ }^{37}$

c. Temperature: Due to the combination of a less robust immune system, decreased cardiac output and decreased muscle mass older adults are often unable to mount a fever response. ${ }^{38}$ For this reason subtle temperature changes, including hypothermia, may indicate a serious infection. ${ }^{39}$

ii) Several factors complicate pain assessment including changes in pain perception, ${ }^{40}$ an increased risk of persistent pain, ${ }^{41}$ and difficulty in assessing patients with cognitive impairment. ${ }^{42}$

iii) Domains of care requiring special consideration include:

a. Atypical presentations of common diseases: Acute coronary syndromes are more likely to present without chest pain. ${ }^{43}$ Sepsis often presents with apparently normal vital signs and non-specific symptoms. ${ }^{44}$ Pneumonia patients are less likely to report respiratory difficulties, pain or febrile response with increasing age. ${ }^{45}$ Patients with an acute surgical abdomen will often report only mild pain. $^{46}$

b. Cognitive impairment: Prospective ED studies of patients over the age of 65 and over 70 have reported rates of delirium of $9.6 \%$ and $10 \%$ respectively. ${ }^{47,48}$ The second study also reported $16 \%$ had mental status impairment and 6\% screened positive for both delirium and dementia. ${ }^{48}$ Many of these patients with delirium went unrecognized by the treating physician and a number were discharged home. Early recognition of acute changes in cognitive behaviour by the triage nurse with communication to the rest of the care team is very valuable.

c. Falls and trauma: ED trauma presentations among the elderly continue to rise along with morbidity and mortality, however, unlike their younger cohorts the major trauma mechanism is falls ${ }^{49}$ often due to general weakness, impaired gait or vision, an acute medical event, medication, or balance issues. ${ }^{50}$ The literature indicates the severity of the injuries, and the impact of comorbidities, among these patients are often underappreciated and as a result, undertriaged. ${ }^{51}$

d. Polypharmacy: Reportedly 44\% of US men and $57 \%$ of US women over the age of 65 are taking 5 or more medications per week making them susceptible to adverse drug events (ADEs). ${ }^{52}$ ADEs account for up to $10 \%$ of elderly ED presentations. Common drug categories causing ADEs include cardiovascular, diuretics, antibiotics, hypoglycemics, sedatives, opioid analgesics, anticholinergics and anti-inflammatory medications. ${ }^{53}$

\section{Paediatric updates}

The fever modifier 'temperature greater than $38.5^{\circ} \mathrm{C}$ looks unwell' CTAS level 2 and 'temperature greater than $38.5^{\circ} \mathrm{C}$ looks well' CTAS level 3 will be limited to children 3-18 months, rather than the previous 3-36 months. Otherwise Paediatric CTAS remains unchanged.

\section{Rationale}

The fever modifier in paediatrics was adopted to capture the vulnerable population for sepsis in childhood. The fever modifier for newborns due to their relative immunodeficiency remains CTAS level 2. There has been a significant change in the incidence of serious infections in young children in relation to the greatly expanded immunization programs across the country. In recognition of the changing patterns of childhood infections, the temperature greater than 
$38.5^{\circ} \mathrm{C}$ fever modifier, which previously included children up to 36 months, will be limited to children 3-18 months. The fever modifier for newborns up to 3 months, due to their relative immunodeficiency, remains CTAS level 2.

\section{Paramedic Chiefs of Canada}

Paramedics across Canada have variably utilized CTAS since the 2004 revisions. Research looking at interrater reliability between EMS providers and ED triage nurses has shown good to moderate agreement. ${ }^{54-56}$ The appropriate application of Pre-CTAS can assist paramedics in clinical decision making and destination decision making. It can also provide an evidence-based rationale for system-wide pre-hospital resource allocation, when combined with dispatch information.

The addition of the Paramedic Chiefs of Canada (PCC) as the sixth member organization to join the CTAS NWG is an important step forward in ensuring the role and value of Pre-CTAS are fully developed. The PCC is an ideal partner as it is comprised of paramedic leaders from all the provinces and territories in Canada with a combined mission to "advance and align paramedic leadership" across the country.

Pre-CTAS is being formally used in Nova Scotia, Ontario, Manitoba, Alberta and Saskatchewan. It is also being applied less-formally in other jurisdictions. To better understand the extent and nature of Pre-CTAS use, the CTAS NWG has circulated an online survey to EMS managers and educators from every province and territory. The survey covered the areas of training, data collection, and details of operational and quality improvement usage.

A consistent educational and operational approach is required to maximize the potential benefits of Pre-CTAS across the country. The CTAS NWG in collaboration with the PCC is publishing a comprehensive overview and update of Pre-CTAS.

\section{Planned CTAS education changes}

\section{Rationale}

To date CTAS education has been provided as a one-day course led by one of more CTAS Instructors. This education has consisted of 4 teaching modules with the last 3 all containing approximately 20 cases which the students work through themselves or in groups while facilitated by the Instructor to ensure everyone understand the principles and can select a relevant presenting complaint and assign an acuity score by applying an appropriate modifier(s). Both nationally and internationally there have been requests for an online educational option as well as a certification indicating a competence in CTAS knowledge, not just a certificate of attendance.

To support the current educational updates an online course is being developed to provide the didactic CTAS knowledge. The content will be a revision of the existing core materials but will also include several major additions. The first is the Geriatric learning section as referenced above. The second is a series of learning modules for each of the CEDIS presenting complaint groups. Both of these will contain sample cases to help clarify key points and each section will have several questions for the learner to complete before moving to the next section. After successful completion of the online component the final training will be a 3-4 hour face-to-face educational session with a CTAS Instructor either in a classroom setting or via distance technology (videoconference/webinar) for rural and remote triage nurses. Some key educational information will be provided or reviewed in these sessions, however, the focus will be in providing more complex cases to generate thoughts and discussion to determine how to most appropriately triage and prioritize each patient, recognizing that you are triaging each patient on their own merit, not the flow or other challenging situations occurring within the emergency department. Upon completion of the face-to-face session and final payment, the Provider or Instructor will receive a certificate of successful completion of CTAS training.

\section{CONCLUSIONS}

While the goal of emergency care providers is always to provide timely access to care, high patient volumes, frequent surges in ED arrivals and system capacity limitations, especially after hours, mean that waits are inevitable. To help provide patient safety and access equity CTAS was developed to assist triage personnel to prioritize patients based on acuity and risk, not to divert patients away. Based on national and international collaborations, 3 new CEDIS complaints have been added along with new modifiers. To better protect our more vulnerable patients a new CTAS level 3 frailty modifier has been introduced. To better address the triage challenges of older patients, new geriatric educational materials have been developed. Heightened 
concerns for serious infections in young children have lessened with vaccinations decreasing the moderate risk age group to 3-18 months.

In addition, the focus has been on revising the educational materials and welcoming the addition of representation from the Paramedic Chiefs of Canada to the CTAS NWG. An online CTAS educational course is being developed to take much of the didactic teaching out of the classroom and focus that time on more challenging case-based discussion to ensure a clear understanding and comfort level applying the CTAS.

Keywords: triage, emergency department, CTAS, revisions, CEDIS, presenting complaint, education, time targets

Conflicts of interest: None to declare.

\section{SUPPLEMENTARY MATERIAL}

To view supplementary material for this article, please visit https://doi.org/10.1017/cem.2017.365

\section{REFERENCES}

1. Beveridge R, Clark B, Janes L, et al. Canadian Emergency Department Triage and Acuity Scale: implementation guidelines. CFEM 1999;1(Suppl):S2-28.

2. Council of the Australasian College for Emergency Medicine. Australasian College for Emergency Medicine policy document. National Triage Scale. Emerg Med 1994;6:145-6.

3. Warren D, Jarvis A, Leblanc L; the National Triage Task Force members. Canadian Paediatric Triage and Acuity Scale: implementation guidelines for emergency departments. CFEM 2001;3(Suppl):S1-27.

4. Grafstein E, Unger B, Bullard $M$, et al. Canadian Emergency Department Information System (CEDIS) Presenting Complaint List (Version 1.0). C7EM 2003;5:27-34.

5. Murray M, Bullard M, Grafstein E. Revisions to the Canadian Emergency Department Triage and Acuity Scale implementation guidelines. CFEM 2004;6:421-7.

6. Grafstein E, Bullard MJ, Warren D, et al. the CTAS National Working Group. Revision of the Canadian Emergency Department Information System (CEDIS) presenting complaint list version 1.1. CFEM 2008;10:151-61.

7. Warren DW, Jarvis A, LeBlanc L, and members of the CTAS National Working Group. Revisions to the Canadian Triage and Acuity Scale Paediatric Guidelines (PaedCTAS). CFEM 2008;10:224-32.

8. Bullard MJ, Unger B, Spence J, and members of the CTAS National Working Group. Revisions to the Canadian Emergency Department Triage and Acuity Scale (CTAS) adult guidelines. CFEM 2008;10:136-42.

9. Bullard MJ, Chan T, Brayman C, and members of the CTAS National Working Group. Revisions to the Canadian emergency department triage and acuity scale (CTAS) guidelines. C7EM 2014;16(6):485-9.
10. Gratton RJ, Bazaracai N, Cameron I, et al. Acuity assessment in obstetrical triage. Obstet Gynaecol Can 2016;38(2):125-33.

11. Affleck A, Parks P, Drummond A, et al. Emergency Department overcrowding and access block. C7EM 2013;15(6): 359-70.

12. Afilalo J, Marinovich A, Afilalo M, et al. Nonurgent emergency department patient characteristics and barriers to primary care. Acad Emerg Med 2004;11(12):1302-10.

13. Han A, Ospina M, Blitz SB, et al. Patients presenting to the emergency department: the use of other health care services and reasons for presentation. CFEM 2007;9(6): 428-34.

14. Vertesi L. Does the Canadian Emergency Department Triage and Acuity Scale identify non-urgent patients who can be triaged away from the emergency department? CFEM 2004;6(5):337-42.

15. Birnbaum A, Gallagher J, Utkewicz M, et al. Failure to validate a predictive model for refusal of care to emergencydepartment patients. Acad Emerg Med 1994;1(3):213-7.

16. Lowe RA, Bindman AB, Ulrich $\mathrm{SK}$, et al. Refusing care to emergency department of patients: evaluation of published triage guidelines. Ann Emerg Med 1994;23(2):286-93.

17. Ng CJ, Liao PJ, Chang YC, et al. Predictive factors for hospitalization of nonurgent patients in the emergency department. Medicine 2016;95(26):e4053.

18. Raven MC, Lowe RA, Maselli J, et al. Comparison of presenting complaint vs. discharge diagnosis for identifying "non-emergency" emergency department visits. 7AMA 2013;309(11):1145-53.

19. Glazer JL. Management of heatstroke and heat exhaustion. Am Fam Physician 2005;71:2133-40.

20. Smith JE. Cooling methods used in the treatment of exertional heat illness. Br 7 Sports Med 2005;39:503-7.

21. Gratton RJ, Bazaracai N, Cameron I, et al. Acuity assessment in obstetrical triage. 7 Obstet Gynaecol Can 2016; 38(2):125-33.

22. Bernstein SL, Aronsky D, Duseja R, et al., Society for Academic Emergency Medicine, Emergency Department Crowding Task Force. The effect of emergency department crowding on clinically oriented outcomes. Acad Emerg Med 2009;16:1-10.

23. Pines JM, Localio AR, Hollander JE, et al. The impact of emergency department crowding measures on time to antibiotics for patients with community-acquired pneumonia. Ann Emerg Med 2007;50:510-6.

24. Diercks DB, Roe MT, Chen AY, et al. Prolonged emergency department stays of non-ST-segment-elevation myocardial infarction patients are associated with worse adherence to the American College of Cardiology/American Heart Association guidelines for management and increased adverse events. Ann Emerg Med 2007;50:489-96.

25. Richardson D. Increase in patient mortality at 10 days associated with emergency department overcrowding. $M \mathcal{F} A$ 2006;184(5):213-6.

26. Guttman A, Schull MJ, Vermeulen MJ, et al. Association between waiting times and short term mortality and hospital admission after departure from emergency department: population based cohort study from Ontario, Canada. BM7 2011;342:d2983. 
27. Inouye SK, Westendorp RGJ, Saczynski JS. Delirium in elderly people. The Lancet 2014;383(9920):911-22.

28. Fong TG, Tulebaev SR, Inouye SK. Delirium in elderly adults: diagnosis, prevention and treatment. Nat Rev Neurol 2009;5(4):210-20.

29. Canadian Study on Health \& Aging, Revised 2008. Abellan van kan G, Rolland Y, Bergman H, et al. on behalf of the geriatric advisory panel ${ }^{\star}$ The I.A.N.A. task force on frailty assessment of older people in clinical practice. The 7 of Nutrit, Health of Aging 2008;12(1):29-37.

30. Rockwood K, Song X, MacKnight C, et al. A global clinical measure of fitness and Frailty in elderly people. CMAJ 2005;173(5):489-95.

31. Aminzadeh F, Dalziel W. Older adults in the emergency department: a systematic review of patterns of use, adverse outcomes, and effectiveness of interventions. Ann Emerg Med 2002;39(3):238-47.

32. Samaras N, Chevalley T, Samaras D, Gold G. Older patients in the emergency department: a review. Ann Emerg Med 2010;56(3):261-9.

33. Krumpe PE, Knudson RJ, Parsons G, et al. The aging respiratory system. Clin Geriatr Med 1985;1(1):143-75.

34. Ridley $S$. The recognition and early management of critical illness. Ann R Coll Surg Engl 2005;87(5):315-22.

35. Gupta V, Lipsitz LA. Orthostatic hypotension in the elderly: diagnosis and treatment. Am $\mathcal{F}$ Med 2007;120(10):841-7.

36. Brown JB, Gestring ML, Forsythe RM, et al. Systolic blood pressure criteria in the National Trauma Triage Protocol for geriatric trauma: 110 is the new 90. 7 Trauma Acute Care Surg 2015;78(2):352-9.

37. Agelink MW, Malessa R, Baumann B, et al. Standardized tests of heart rate variability: normal ranges obtained from 309 healthy humans, and effects of age, gender, and heart rate. Clin Auton Res 2001;11(2):99-108.

38. Sund-Levander M, Grodzinsky E. Time for a change to assess and evaluate body temperature in clinical practice. Int 7 Nurs Pract 2009;15(4):241-9.

39. Keating HJ 3rd, Klimek JJ, Levine DS, et al. Effect of aging on the clinical significance of fever in ambulatory adult patients. 7 Am Geriatr Soc 1984;32(4):282-7.

40. Moore AR, Clinch D. Underlying mechanisms of impaired visceral pain perception in older people. FAGS 2004;52:132-6.

41. Gibson SJ, Farrell M. A review of age differences in the neurophysiology of nociception and the perceptual experience of pain. Clin 7 Pain 2004;20:227-39.

42. Zwakhalen SM, Hamers JP, Abu-Saad HH, Berger MP. Pain in elderly people with severe dementia: a systematic review of behavioural pain assessment tools. BMC Geriatrics 2006;6:3.

43. Coronado BE, Pope JH, Griffith JL, et al. Clinical features, triage, and outcome of patients presenting to the ED with suspected acute coronary syndromes but without pain: a multicenter study. Am 7 of Emerg Med 2004;22(7):568-74.

44. Metlay JP, Schulz R, Li YH, et al. Influence of age on symptoms at presentation in patients with communityacquired pneumonia. Arch Intern Med 1997;157:1453-9.

45. Lim WS, Macfarlane JT. Defining prognostic factors in the elderly with community acquired pneumonia: a case controlled study of patients aged $\geq 75$ yrs. Eur Respir 7 2001;17: 200-5.

46. Samaras N, Chevalley T, Samaras D, et al. Older patients in the emergency department: a review. Ann Emerg Med 2010;56(3):261-9.

47. Elie M, Rousseau F, Cole M, et al. Prevalence and detection of delirium in elderly emergency department patients. CMA7 2000;163:977-81.

48. Hustey FM, Meldon SW. The prevalence and documentation of impaired mental status in elderly emergency department patients. Ann Emerg Med 2002;39:248-53.

49. Centers for Disease Control. Falls Among Older Adults: An Overview. Available at: http://www.cdc.gov/Homeand RecreationalSafety/Falls/adultfalls.html. Accessed July 19, 2016.

50. Bonne S, Schuerer DJE. Trauma in the older adult: epidemiology and evolving geriatric trauma principles. Clin Geritr Med 2013;29:137-50.

51. Chang DC, Bass RR, Cornwell EE, et al. Undertriage of elderly trauma patients to state-designated trauma centers. Arch Surg 2008;8:776-81.

52. Haynes BD, Klein-Schwartz W, Barreuto F. Polypharmacy and the geriatric patient. Clin Geriatr Med 2007;23:371-90.

53. Gurwitz JH, Field TS, Harrold LR, et al. Incidence and preventability of adverse drug events among older persons in the ambulatory setting. $7 A M A$ 2003;289:1107-16.

54. Murray M, Bondy S. The reliability of the Canadian triage and acuity scale in the prehospital setting: Interrater reliability between paramedics and nurses [abstract]. CFEM 2002;4:128.

55. Manos D, Petrie DA., Beveridge RC, et al. Inter-observer agreement using the Canadian Emergency Department Triage and Acuity Scale. CFEM 2002;4(1):16-22.

56. Leeies M, Weldon E, Strome T, et al. Prehospital application of the Canadian Triage and Acuity Scale by emergency medical service. CFEM 2016;19(1):26-31. 